\title{
Hibridização no ensino superior: avaliação de uma iniciativa na disciplina Introdução à Administração (Universidade de Brasília)
}

\author{
Helena Costa \\ Universidade de Brasília, helenacosta@unb.br \\ Késia Rozzett \\ Universidade de Brasília, kesiaro@gmail.com \\ Sílvia Carvalho \\ Universidade de Brasília, silvinha29@ hotmail.com \\ Catarina Odelius \\ Universidade de Brasília, codelius@unb.br
}

Diferentes combinações nos usos de Tecnologias de Informação e Comunicação (TICs) têm sido testadas em Instituições de Ensino Superior, mas poucos são os relatos que indicam seus benefícios e dificuldades. O objetivo deste trabalho é analisar a experiência de hibridização da disciplina Introdução à Administração da UnB. A partir do benchmarking realizado por Costa, Rozzett e Carvalho (2012), que analisou boas práticas em hibridização no ensino superior, foram identificados quinze aspectos relevantes para o sucesso de tais iniciativas, que subsidiaram a elaboração de um plano de ensino híbrido que foi implementado. Ao final da disciplina, foram avaliadas as percepções dos alunos, professores e tutores envolvidos, por meio de questionários aplicados aos discentes e realização de grupo focal com os docentes e tutores. De forma geral, o modelo de hibridização mostrou-se satisfatório, com aprovação de mais de $80 \%$ dos alunos. Os resultados evidenciaram dificuldades como: falta de infraestrutura; distribuição pulverizada das notas; participação nos fóruns no último minuto, entre outras. Entre os pontos fortes estão: facilidade de utilização, acesso a arquivos, e organização e interação. O trabalho contribui para a literatura, já que há carência de estudos empíricos e propositivos que guiem a implementação prática de novos projetos de hibridização.

Palavras-chave: hibridização de disciplinas, blended learning, aprendizagem híbrida, tecnologias de informação e comunicação, ensino superior

\section{Hybridization in higher education: evaluation of an initiative in the course Introduction to Management (University of Brasília)}

Different combinations in the use of Information and Communication Technologies (ICTs) have been tested in Higher Education Institutions, but there are few reports that indicate its benefits and difficulties. The objective of this paper is to analyze the hybridization experience in the course Introduction to Management at the University of Brasília. From the benchmarking done by Costa, Rozzett and Carvalho (2012), which examined best practices in hybridization in higher education, fifteen important aspects were identified for the success of such initiatives and gave support to the development of a hybrid teaching plan that was implemented. At the end of the course, the perceptions of students, teachers and tutors involved were evaluated through questionnaires given to students and focus groups with teachers and tutors. Overall, the hybrid model developed was satisfactory, with the approval of more than $80 \%$ of the students. The results showed difficulties such as lack of infrastructure, final grade distributed into many activities, participation in forums at the last minute, among others. 
Some of the strengths identified were: ease of use, access to files, organization and interaction. The paper contributes to the literature gap of empirical studies and proposals that guide the practical implementation of new hybridization projects.

Keywords: Courses hybridization, blended learning, hybrid learning, information communication and technologies, higher education

\section{Introdução}

A aprendizagem híbrida, ou blended learning, é entendida como uma situação de aprendizagem que combina diversos métodos, entre eles a educação a distância intermediada por Tecnologias de Informação e Comunicação (TICs), em busca de uma experiência instrucional mais eficiente, em termos de uso de recursos, e eficaz na consecução dos resultados almejados (El-Deghaidy \& Nouby, 2008; Singh, 2003). Para Singh (2003), uma nova onda de e-learning, caracterizada por um número cada vez maior de modelos híbridos que combinam vários modos de interação, está surgindo. Em consonância, o trabalho de Gomes Filho, Rados e Bastos (2007) apresenta o blended learning como uma tendência do ensino atual que consiste na combinação de recursos didáticos provenientes das TICs ao tradicional ensino na sala de aula como um meio para assegurar o máximo de eficiência e eficácia no ensino e na aprendizagem. Ao comparar as modalidades híbrida e tradicional, Rovai e Jordan (2004) afirmam que a primeira possui maior potencial para proporcionar aprendizagem significativa aos estudantes do ensino superior.

Diferentes níveis de combinação têm sido testados em Instituições de Ensino Superior (IES), mas são poucos os relatos de experiência que indicam de forma mais pragmática os benefícios ou dificuldades encontradas na hibridização.

Nesse sentido, foi feita uma experiência de hibridização em uma turma com alunos do curso de Administração da Universidade de Brasília como parte de uma das atividades de apoio ao Projeto de Desenvolvimento e Apropriação de Tecnologias de Informação e Comunicação no Departamento de Administração da Universidade de Brasília'. Assim, o objetivo deste artigo é apresentar a percepção dos alunos, professores e tutores a respeito da implementação do modelo de hibridização desenhado para a disciplina Introdução à Administração.

\section{Metodologia}

Ao início da disciplina Introdução à Administração, foi lançado no Ambiente Virtual de Aprendizagem (AVA) um questionário destinado a conhecer o perfil tecnológico e sociodemográfico dos estudantes. A primeira parte do instrumento continha sete questões que objetivavam identificar características como: faixa etária, sexo, turno, semestre, posse de laptop, fonte de acesso à internet e renda mensal familiar. Em seguida, duas questões com doze itens, cada, buscavam conhecer o grau de domínio e conhecimento de diversas TICs. O questionário ficou disponível para resposta por aproximadamente quinze dias.

Ao final da disciplina, um outro questionário, com 27 questões, foi aplicado aos alunos no intuito de avaliar a contribuição das TICs utilizadas na disciplina e a

\footnotetext{
${ }^{1}$ Conforme o edital no. $15 / 2010$ da CAPES.
} 
satisfação dos discentes em relação a estas ferramentas. Havia 26 itens a serem respondidos em escala de concordância (tipo Likert), onde o aluno deveria marcar um número entre 1 e 5 , sendo que 1 representava "discordo totalmente" e 5 , "concordo totalmente". A última questão foi aberta e facultativa, com espaço para sugestões, críticas, elogios e outros comentários que os alunos achassem pertinentes em relação à experiência com a disciplina. As questões foram analisadas com apoio de técnicas descritivas de estatística, conforme instruções de Field (2009).

O questionário diagnóstico buscou traçar o perfil dos alunos e conhecer o nível de conhecimento, utilização e domínio quanto a algumas TICs. Dos 60 alunos matriculados na disciplina, 36 responderam ao questionário, indicando uma participação de aproximadamente $50 \%$ da turma. A participação foi abaixo do esperado e pode ser atribuída ao fato de que o questionário não era obrigatório entre as atividades da disciplina. Soma-se a este fato, a aplicação virtual do instrumento nos primeiros dias de aula e seu encerramento na semana anterior à primeira atividade avaliativa no ambiente virtual.

Em relação ao perfil dos estudantes, 23 respondentes $(63,9 \%)$ eram do sexo feminino e $13(36,1 \%)$, do sexo masculino. A faixa etária da maioria era entre 17 e 21 anos $(91,7 \%)$, com as exceções de um aluno de até 16 anos $(2,8 \%)$ e 2 alunos de 22 a 26 anos $(5,6 \%)$. Todos os 36 respondentes eram do curso diurno e praticamente todos os alunos $(97,2 \%)$ eram do primeiro semestre, com apenas uma pessoa $(2,8 \%)$ do segundo semestre. A distribuição da faixa etária, turno e semestre pareceram ser um bom indicador da turma como um todo, visto que a disciplina é destinada a calouros do curso de Administração diurno.

Ao término do semestre, foi conduzido um grupo focal com professores e tutores envolvidos na atividade de hibridização a fim de analisar os erros e acertos do modelo implementado.

\section{Resultados}

\section{Perfil tecnológico e social da turma}

Uma vez que algumas atividades no Ambiente Virtual de Aprendizagem (AVA) funcionaram em substituição (no mesmo horário) à aula presencial, algumas questões buscaram conhecer como se dava o acesso à Internet da maioria dos alunos no sentido de planejar como a turma poderia conectar-se nos horários dos chats.

Mais de $60 \%$ dos alunos disseram acessar à Internet de casa, enquanto aproximadamente $20 \%$ utilizavam a rede na Universidade. Apesar de parte dos alunos terem disponibilidade de acesso à internet, foi necessário providenciar o acesso na própria universidade, uma vez que os alunos estariam em sala de aula no horário anterior ao agendado para a atividade síncrona no AVAA figura 1 evidencia os locais de acesso à Internet geralmente utilizados pelos alunos. 


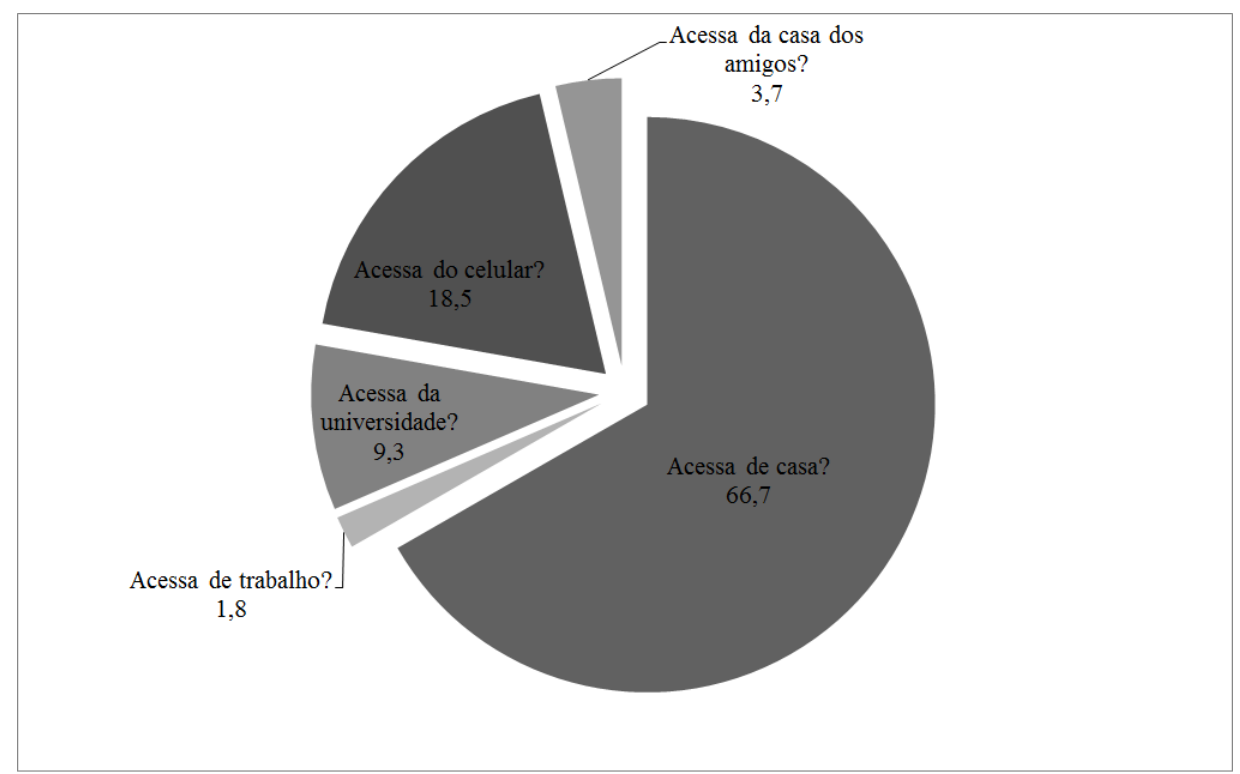

Figura 1: Locais de acesso à Internet

Ainda visando entender quais seriam as possíveis dificuldades que os alunos poderiam ter ao acessar à Internet para realização das atividades, investigou-se se eles possuíam laptops. Dos 36 respondentes, 23 (63,9\%) disseram ter computadores portáteis, o que poderia ser considerado um facilitador para a participação não fosse a instabilidade da rede sem fio da Universidade, principalmente nos meses de abril, maio e junho de 2011.

Em relação à renda familiar, 44,44\% dos alunos pertence à classe $\mathrm{A}$, enquanto os outros $55,56 \%$ estão distribuídos entre as classes B e C, conforme a figura 2.

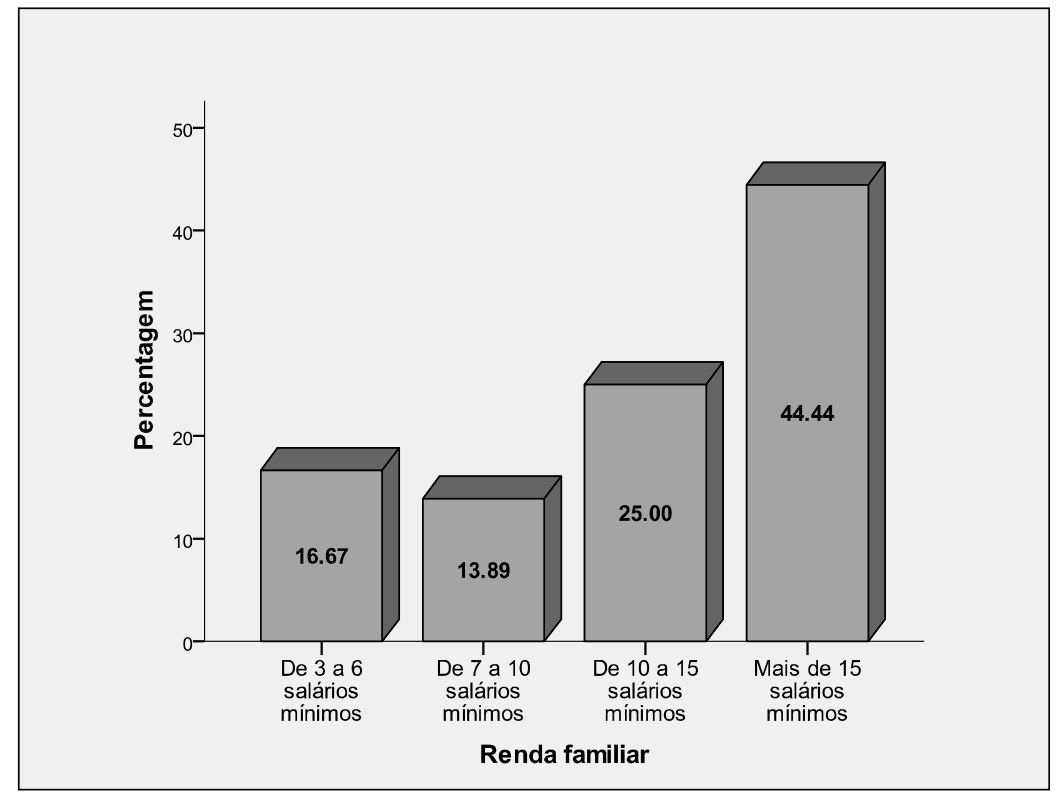

Figura 2: Renda familiar

A parte seguinte da análise pretendia investigar o nível de domínio, conhecimento e utilização de certas TICs por parte dos novos alunos. Foram elaborados 12 itens que avaliavam a navegação por ambientes de aprendizagem; a utilização de processadores de textos, sistemas de buscas, editores de apresentação e editores de páginas da web; a participação em chats, videoconferências e listas de discussão, a 
edição de blogs, a contribuição a atividades coletivas de aprendizagem, o acesso a podcasts e o gerenciamento de perfis em redes sociais.

Para avaliar o domínio destas TICs, utilizou-se uma escala do tipo Likert, com cinco pontos, em que: 1 representava nenhum domínio; 2 representava pouco domínio; 3 representava domínio razoável; 4 representava muito domínio; e 5 representava domínio completo. A tabela 1 apresenta as medidas de moda e mediana para cada uma das questões.

Tabela 1 - Mediana e moda das questões sobre domínio das TICs

\begin{tabular}{lrr}
\hline \multicolumn{1}{c}{ Item } & Mediana & Moda \\
\hline Navegar pelo moodle e outros ambientes de aprendizagem & 3 & 3 \\
\hline Utilizar processadores de texto & 3 & 3 \\
\hline Utilizar sistemas de buscas & 4 & 4 \\
\hline Participar de chats & 4 & 4 \\
\hline Participar de videoconferências & 2,5 & 2 \\
\hline Utilizar editor de apresentações & 3 & 3 \\
\hline Utilizar editores de paginas web & 1 & 1 \\
\hline Editar blogs & 2,5 & 1 \\
\hline Participar de listas de discussão & 3 & 2 \\
\hline Contribuir em atividades coletivas de aprendizagem & 2 & 2 \\
\hline Acessar podcasts & 2 & 1 \\
\hline Gerenciar perfil em redes sociais & 5 & 5 \\
\hline
\end{tabular}

Apesar de os alunos terem respondido o questionário no primeiro mês de aula e de a maioria nunca ter utilizado ambientes virtuais de aprendizagem (AVA) antes (conforme arguição informal em sala de aula e o perfil de alunos calouros), 44,5\% dos respondentes disse possuir muito domínio ou domínio completo na navegação pelo moodle e outros AVAs e outros $44,4 \%$ disseram possuir um domínio razoável. É possível que a ministração de uma aula instrucional sobre as ferramentas do moodle possa ter elevado a percepção sobre o nível de domínio de ambientes virtuais por parte dos alunos.

Para avaliar o nível de conhecimento e utilização das TICs, utilizou-se uma escala do tipo Likert, com quatro pontos, em que: 1 representava "não conheço"; 2 representava "conheço, mas não utilizo"; 3 representava "conheço e utilizo para questões pessoais"; e 4 representava "conheço e utilizo em meus estudos". A tabela 2 apresenta as frequências de resposta para cada uma das questões.

Tabela 2 - Frequência relativa de respostas sobre conhecimento e utilização de TICs (\%)

\begin{tabular}{lrrrrrr}
\hline \multicolumn{1}{c}{ Item } & $\begin{array}{c}\text { Não } \\
\text { conheço }\end{array}$ & $\begin{array}{c}\text { Conheço, } \\
\text { mas não } \\
\text { utilizo }\end{array}$ & $\begin{array}{c}\text { Conheço e utilizo } \\
\text { para questões } \\
\text { pessoais }\end{array}$ & $\begin{array}{c}\text { Conheço e } \\
\text { utilizo em } \\
\text { meus estudos }\end{array}$ & Total \\
\hline $\begin{array}{l}\text { Navegar pelo moodle e outros } \\
\text { ambientes de aprendizagem }\end{array}$ & 0 & 0 & 2,8 & 97,2 & 100 \\
\hline Utilizar processadores de texto & 0 & 11,1 & 8,3 & 80,6 & 100 \\
\hline Utilizar sistemas de buscas & 0 & 2,8 & 30,6 & 66,7 & 100 \\
\hline Participar de chats & 0 & 50,0 & 50,0 & 0 & 100 \\
\hline
\end{tabular}




\begin{tabular}{lrrrrr}
\hline Participar de videoconferências & 8,3 & 63,9 & 27,8 & 0 & 100 \\
\hline Utilizar editor de apresentações & 2,8 & 16,7 & 2,8 & 77,8 & 100 \\
\hline Utilizar editores de paginas web & 69,4 & 30,6 & 0 & 0 & 100 \\
\hline Editar blogs & 19,4 & 52,8 & 19,4 & 8,3 & 100 \\
\hline Participar de listas de discussão & 2,8 & 58,3 & 22,2 & 16,7 & 100 \\
\hline $\begin{array}{l}\text { Contribuir em atividades } \\
\text { coletivas de aprendizagem }\end{array}$ & 16,7 & 61,1 & 11,1 & 11,1 & 100 \\
\hline Acessar podcasts & 41,7 & 36,1 & 16,7 & 5,6 & 100 \\
\hline Gerenciar perfil em redes sociais & 0 & 8,3 & 88,9 & 2,8 & 100 \\
\hline
\end{tabular}

Em relação à navegação no moodle e em outros ambientes virtuais de aprendizagem, dos 36 respondentes, 35 afirmaram que conhecem e utilizam em seus estudos e apenas 1 disse conhecer e utilizar para questões pessoais. Novamente, os alunos alegaram utilizar ambientes virtuais de aprendizagem em seus estudos antes mesmo das atividades obrigatórias da disciplina se iniciarem, indicando uma facilidade em adotar este tipo de TIC no ensino.

\section{Percepção dos alunos sobre a utilização das TICs na disciplina Introdução à Administração}

Ao final da disciplina, foi aplicado um segundo questionário que visava buscar a percepção dos alunos sobre a utilização de TICs na disciplina (satisfação, aproveitamento, avaliação, possibilidade de utilização em outras disciplinas). Os resultados deste questionário permitiram um olhar reflexivo sobre a experiência híbrida a partir da opinião dos alunos.

$\mathrm{Na}$ grade de questões avaliadas quanto ao grau de concordância, foram incluídos 7 itens em que o aluno deveria escolher um ponto entre 1 e 5 para indicar sua satisfação com aspectos específicos da utilização de TICs na disciplina, onde 1 representava "discordo totalmente" e 5, "concordo totalmente".

A tabela 3 mostra a mediana e moda das respostas dos alunos, indicando sua satisfação quanto aos quesitos propostos, onde:

Tabela 3 - Mediana e moda das respostas sobre satisfação com o uso das TICs em Introdução à Administração

\begin{tabular}{ccc}
\hline Item & Mediana Moda \\
\hline Estou satisfeito com a disponibilização do calendário das atividades no moodle & 5 & 5 \\
\hline Estou satisfeito com a disponibilização dos arquivos no moodle & 5 & 5 \\
\hline Estou satisfeito com a comunicação (quadro de avisos) via moodle & 5 & 5 \\
\hline Estou satisfeito com o apoio da tutoria/monitoria & 4 & 4 \\
\hline $\begin{array}{c}\text { Estou satisfeito com a infraestrutura oferecida pela UnB para utilização do } \\
\text { moodle (rede sem fio, computadores, laboratórios, auditório) }\end{array}$ & 4 & 5 \\
\hline $\begin{array}{c}\text { Em geral, estou satisfeito com a adoção do moodle para esta disciplina } \\
\text { No geral, estou satisfeito com a disciplina }\end{array}$ & 5 \\
\hline
\end{tabular}


A tabela 4 apresenta a frequência das respostas dos alunos quanto à satisfação com o uso da TICs.

Tabela 4 - Frequência relativa das respostas sobre satisfação com o uso das TICs em Introdução à Administração (\%)

\begin{tabular}{lcccccc}
\hline \multicolumn{1}{c}{ Item } & $\begin{array}{c}\text { Discordo } \\
\text { totalmente }\end{array}$ & 2 & 3 & 4 & $\begin{array}{c}\text { Concordo } \\
\text { totalmente }\end{array}$ & Total \\
\hline $\begin{array}{l}\text { Estou satisfeito com a disponibilização } \\
\text { do calendário das atividades no moodle }\end{array}$ & 0 & 4.4 & 6.7 & 26.7 & 62.2 & 100.0 \\
$\begin{array}{l}\text { Estou satisfeito com a disponibilização } \\
\text { dos arquivos no moodle }\end{array}$ & 0 & 4.4 & 15.6 & 20.0 & 60.0 & 100.0 \\
$\begin{array}{l}\text { Estou satisfeito com a comunicação } \\
\text { (quadro de avisos) via moodle }\end{array}$ & 0 & 4.4 & 6.7 & 24.4 & 64.4 & 100.0 \\
$\begin{array}{l}\text { Estou satisfeito com o apoio da } \\
\text { tutoria/monitoria }\end{array}$ & 0 & 6.7 & 15.6 & 40.0 & 37.8 & 100.0 \\
$\begin{array}{l}\text { Estou satisfeito com a infraestrutura } \\
\text { oferecida pela UnB para utilização do }\end{array}$ & 4.4 & 15.20 .0 & 28.9 & 31.1 & 100.0 \\
$\begin{array}{l}\text { moodle (rede sem fio, computadores, } \\
\text { laboratórios, auditório) }\end{array}$ & & 6 & & & & \\
$\begin{array}{l}\text { Em geral, estou satisfeito com a adoção } \\
\text { do moodle para esta disciplina }\end{array}$ & 0 & 4.4 & 6.7 & 26.7 & 62.2 & 100.0 \\
$\begin{array}{l}\text { No geral, estou satisfeito com a disciplina } \\
\text { no }\end{array}$ & 0 & 2.2 & 8.9 & 20.0 & 68.9 & 100.0 \\
\hline
\end{tabular}

No geral, os resultados foram positivos, visto que em nenhuma questão o índice de discordância foi maior que o de concordância. As medidas de tendência central (mediana e moda) também indicam a satisfação dos alunos. As questões com maior porcentagem de concordância $(88,9 \%)$ foram as de satisfação geral e de satisfação com a disponibilização do calendário no moodle. É provável que o nível de satisfação com esta última tenha sido alto pelo fato de que a disciplina recebeu diagramação especial para apresentar o conteúdo semanal no moodle, disponibilizando aos alunos os textos, assuntos e atividades estudados em sala durante todo o semestre. Já em relação à maior insatisfação, a questão destacada (a única com frequência em "discordo totalmente") refere-se à infraestrutura disponibilizada pela UnB para a utilização do moodle: $20 \%$ dos alunos declaram não estarem satisfeitos com este aspecto, o que é condizente com o temor inicial dos professores e tutores a respeito do suporte necessário para a realização de uma disciplina híbrida. Apesar de possuir uma rede sem fio para que discentes e docentes tenham acesso livre à Internet, a universidade deixa a desejar com uma rede que sofre grande instabilidade e disponibiliza poucos computadores para uso livre.

A questão final do questionário, de resposta facultativa, teve participação satisfatória dos alunos, visto que quase metade da turma fez algum tipo de comentário.

Entre os elogios, os discentes citaram, entre outros aspectos, a coerência em relação aos objetivos propostos; utilização proveitosa do moodle; contribuição dos trabalhos desenvolvidos para o aprendizado e a dinamicidade das aulas; conteúdo e proposta dos fóruns temáticos; diversificação e criatividade das atividades; transmissão do filme; qualidade das aulas presenciais; empenho e atenção da professora; a metodologia de ensino. Dentre estes, o mais citado foi o fato de a disciplina ter sido semipresencial e o quanto esta abordagem diferenciada contribuiu com o aprendizado.

Quanto às críticas ao modelo aplicado, os alunos mencionaram principalmente as dificuldades com o chat do moodle, citando-o como "perda de tempo, uma vez que 
tende naturalmente ao caos", "irrelevante", "bagunçado" e que "deixou a desejar". Foram citadas também a falta de boa infraestrutura na Universidade (disponibilidade de computadores e internet) para que eles participassem das aulas virtuais no horário de aulas e a pouca interação dos alunos no fórum. Um discente citou, ainda, a demora dos monitores/tutores para responder o fórum de dúvidas. Por fim, um aluno comentou que "os fóruns são interessantes, porém não se comparam a boa e velha sala de aula", refletindo, de certo modo, a resistência que ainda existe em relação à utilização de TICs para a aprendizagem.

Entre as sugestões dos alunos, estão: realização de mais fóruns e atividades virtuais; aperfeiçoamento do chat, com divisão da turma em pequenos grupos; disponibilização de uma lista de livros da área de Administração; maior atenção ao fórum de dúvidas por parte dos monitores/tutores; e expansão do projeto de disciplinas semipresenciais para outras disciplinas do curso. Houve opiniões discrepantes enquanto um aluno sugeriu que mais fóruns fossem realizados, outro disse que uma das atividades ou fóruns poderia ter sido feita em sala de aula -, mas, no geral, os alunos demonstraram acreditar no modelo híbrido e em seu potencial de aperfeiçoamento para o ensino superior.

\section{Percepção dos professores e tutores}

Ao final do semestre, foi conduzido um grupo focal com os professores e tutores envolvidos na atividade a fim de avaliar, de forma geral, a contribuição das TICS utilizadas para melhor aprendizagem e os aspectos positivos e negativos da experiência.

Um ponto levantado como beneficiador no processo de aprendizagem foi a divisão da turma - a princípio grande, com mais de 60 alunos - em três grupos menores (com aproximadamente 20 alunos, cada) para fins de discussões no fórum e realização de atividades no ambiente virtual. Cada tutora ficou responsável por um grupo e um monitor auxiliou na compilação das notas e atividades em uma planilha única. As tutoras perceberam que a divisão em grupos menores possibilitou um contato mais individualizado com os alunos nos fóruns, estimulando a troca de informações e experiência personalizada, despertando, assim, maior interesse dos discentes e enriquecimento da discussão.

De forma geral, os fóruns temáticos tiveram um bom índice de participação com duas ou mais postagens por aluno e estímulo constante por parte do tutor ao confronto de ideias, exposição de experiências diversificadas e conversa entre os colegas. As tutoras davam retorno às mensagens postadas em menos de 24 horas, o que pode ter sido um fator incentivador desta participação contínua. Este prazo, contudo, não era seguido nos fóruns de dúvidas e sugeriu-se que apenas um monitor ficasse responsável por este fórum a fim de evitar longos períodos sem respostas aos alunos.

Apesar da boa participação nos fóruns temáticos, levantou-se um questionamento sobre as postagens dos alunos, sugerindo que este processo de deixar uma mensagem e voltar algumas horas depois para continuar a discussão poderia ser, em sua maioria, apenas um reflexo do sistema de avaliação adotado, que contava, entre outros aspectos, a participação frequente do aluno na discussão. Cabe ressaltar, todavia, que prevaleceu na avaliação dos fóruns de discussão o critério de qualidade na participação e que não houve reclamação de notas por parte dos alunos.

As tutoras destacaram, também, a dificuldade com o formato do terceiro fórum avaliativo, que não estimulou a discussão entre os alunos (em duplas, os alunos analisavam um estudo de caso escolhido pela professora, escolhiam uma das perguntas ao final do caso e, então, postavam a resposta no fórum). 
No que diz respeito ao nível de dificuldade das atividades, as professoras e tutoras concordaram que havia equivalência com o que era ensinado em sala de aula, mas que havia um nível de exigência com o qual eles provavelmente não estavam acostumados, visto que a maioria encontrava-se no primeiro semestre de graduação. A leitura de artigos científicos, a elaboração do trabalho final no formato de trabalho científico, a adoção das normas da ABNT, entre outros aspectos, elevaram o grau de dificuldade das atividades. Neste sentido, ressaltou-se que a pontuação deve ser proporcional ao esforço requerido para a realização da tarefa. As professoras e tutoras entenderam que a falta de participação em atividades como o resumo e discussão de artigos no fórum podem não ter tido adesão de alguns alunos por conta da baixa pontuação atribuída, principalmente ao final da disciplina (o terceiro fórum, por exemplo, valia apenas 1 ponto, de um total de 100), quando os esforços estavam concentrados na elaboração do trabalho final e no estudo para avaliações finais de outras matérias.

\section{Conclusões}

O modelo adotado mostrou-se satisfatório a partir das percepções de professores, tutores, monitores e alunos envolvidos, sendo um passo em direção a modelos mais incrementados de disciplinas híbridas no ensino superior.

As dificuldades encontradas englobam: a falta de infraestrutura adequada para a utilização do moodle pelos alunos na universidade; a distribuição pulverizada das notas entre as atividades a distância; o formato de um dos fóruns temáticos, que não contribuiu para interação entre os alunos; a falta de qualidade no sistema para utilização do chat; a tendência dos alunos em participar dos fóruns no último minuto, sem real contribuição para a discussão, e a dificuldade em reverter este quadro.

Como pontos fortes, foram destacadas a atividades de leitura e análise de artigos científicos, as contribuições nos fóruns de discussão, a facilidade de utilização, acesso a arquivos e organização da disciplina no moodle, e a interação entre os tutores, monitores e alunos.

Espera-se que este modelo seja replicado e adaptado para outras disciplinas ou cursos nas Instituições de Ensino Superior, aperfeiçoando os pontos de dificuldade e reforçando os acertos da experiência em Introdução à Administração.

$\mathrm{O}$ custo de operacionalização da proposta, principalmente pela intensa necessidade de supervisão por parte de um professor qualificado, pela quantidade de tutores utilizada (um tutor para 20 alunos), e a possível necessidade de capacitá-los antes pode ser um dificultador na replicação do modelo e deve ser analisado. Além disso, é preciso que a universidade ofereça uma infraestrutura que dê suporte à utilização das TICs por parte dos alunos enquanto estiverem no campus.

Como limitações desta pesquisa, tem-se o baixo índice de respostas no primeiro questionário e o fato de o grupo focal agendado com os alunos não ter acontecido por baixo quórum.

Em futuras pesquisas, sugere-se que este modelo seja replicado e adaptado a fim de melhorar sua aderência e testar sua validade. Também se recomenda que novos estudos sejam feitos com caráter longitudinal, possibilitando, desta forma, uma análise mais aprofundada da real efetividade das TICs na contribuição ao aprendizado.

\section{Referências}

COSTA, H. A.; ROZZETT, K.; CARVALHO, S. S. Hibridização de disciplinas no

Ensino Superior presencial: benchmarking e proposta de programa da disciplina Introdução a Administração. In: ALFINITO, S.; PASCHOAL, T.; MADURO-ABREU, 
A. M.; CANTAL, C. B. R. (Orgs.). Aplicações e tendências do uso de Tecnologias de Informação e Comunicação na Educação Superior presencial no Brasil. Brasília: Universidade de Brasília, Departamento de Administração da Faculdade de Economia, Administração e Contabilidade, 2012. Cap. 3.

EL-DEGHAIDY, H.; NOUBY, A. Effectiveness of a blended e-learning cooperative approach in an Egyptian teacher education programme. Computers \& Education, v. 51, n. 3, p. 988-1006, nov. 2008.

FIELD, A. Discovering statistics using SPSS. 3. ed. Londres: Sage Publication, 2009.

GOMES FILHO, A. C.; RADOS, G. J. V; BASTOS, R. C. Tecnologias da informação e comunicação no apoio ao ensino de empreendedorismo e projetos. Revista Gestão Industrial (online), v. 3, n. 4, p. 52-69, 2007. Disponível em <http://www.pg.utfpr.edu.br/depog/periodicos/index.php/revistagi/article/view/44/41> Acesso em 15 jan. 2011.

ROVAI, A.P.; JORDAN, H. M. Blended learning and sense of community: a comparative analysis with traditional and fully online graduate courses. The International Review of Research in Open and Distance Learning, v. 5, n. 2, abr. 2004. Disponível em <http://www.irrodl.org/index.php/irrodl/article/viewArticle/192/274.\%20Accessed\% 2019th\%20March\%202006> Acesso em 26 nov. 2010.

SINGH. Building effective blended learning programs. Educational Technology, v. 43, n. 6, p. 51-54, 2003. 